\title{
Residual stress analysis in orthogonal machining of standard and resulfurized AISI 316L steels
}

\author{
R. M'Saoubi ${ }^{\mathrm{a}}$, J.C. Outeiro ${ }^{\mathrm{b}}$, B. Changeux ${ }^{\mathrm{a}}$, J.L. Lebrun ${ }^{\mathrm{a}}$, A. Morão Dias ${ }^{\mathrm{b}, *}$ \\ a'LM3, URA CNRS 1219, Ecole Nationale Supérieure d'Arts et Métiers, 151 Boulvard de l'Hôpital, 75013 Paris, France \\ ${ }^{\mathrm{b}}$ Departamento de Engenharia Mecânica, Universidade de Coimbra, Pinhal de Marrocos, 3030 Coimbra, Portugal
}

Received 21 June 1998

\begin{abstract}
Residual stresses induced by orthogonal cutting in AISI 316L standard and resulfurized steels have been investigated, with attention given to the role played by the cutting parameters, such as cutting speed, feed rate, tool geometry and tool coating. Depth profiles of residual stress have been determined using the X-ray diffraction technique. The effect of cutting conditions and tool nature on residual stresses are analyzed in association with thermal and mechanical events, recorded during the cutting tests. The tool temperature distribution has been determined by a specific CCD infrared camera technique and the cutting forces by a Kistler table set up on the lathe. (C) 1999 Elsevier Science S.A. All rights reserved.
\end{abstract}

Keywords: Austenitic stainless steel; Machining; Residual stress; Cutting forces; Tool temperature

\section{Introduction}

Austenitic stainless steels have many applications because of their high corrosion and oxidation resistance properties. However, these materials are considered difficult to machine because of specific properties such as high mechanical and microstructural sensitivity to strain and stress rates. They are prone to work-hardening, which induces mechanical modifications and behavioral heterogeneity on the machined surface, and leads to unstable chip formation and vibrations. Moreover, their low thermal conductivity leads to bad heat conduction at the tool tip and, locally, to very hot points. These thermo-mechanical phenomena affect the surface integrity of the piece.

Free cutting austenitic stainless steels with high sulfur content have been developed in order to facilitate cutting operations. Their better machinability is related to the plastic behavior of the sulfides in the flow zone [1]. However, adding this element is detrimental to corrosion resistance and material workability. Consequently, special attention was paid to the development of both calcium- and sulfurcontrolled austenitic stainless steels. Their addition

\footnotetext{
*Corresponding author. Tel.: 351-39-790-759; fax: 351-39-790-701
} E-mail address: gtr@gemini.ci.uc.pt (A. Morão Dias) improves machinability without greatly reducing resistance to corrosion. Further, the development of new materials for cutting tools, such as TiN-coated cemented tungsten carbides, has also led to better control of the material removal process.

An important factor related to the workpiece surface alteration occurring during machining is the residual stress distribution. Indeed, it can greatly affect the material's properties and its ability to withstand severe loading conditions (stress corrosion cracking, fatigue, ...). The nature of residual stresses depends not only on machining parameters such as the cutting speed, feed rate, depth of cut, but also on the tool geometry and the lubrication conditions.

Residual stresses resulting from metal removal processes have been studied for several decades. Henriksen [2] attributed residual stresses mainly to mechanical effects caused by the forces acting on the tool during the cutting process, deeming thermal stresses due to heat generation to be negligible. However, another study performed by Okushima and Kakino [3] showed that tensile residual stresses were caused by thermal effects and compressive residual stresses by mechanical effects related to the machining operation. The later results obtained by Liu and Barash [4] tend to validate Henriksen's conclusions.

Recent works on carbon steel have also shown that the nature of the residual stresses produced on a machined 
surface is related to the material properties, especially its hardness. Matsumoto et al. [5] showed that the residual stresses obtained from the machining of AISI 4340 steel are tensile for low hardness levels but become compressive as hardness increases. For the same material, Wu and Matsumoto [6] showed that the residual stress pattern is linked to the orientation of the primary shear deformation zone in metal cutting. In most cases, a tensile residual stress state is found on the machined surface. Brinksmeier and Scholtes $[7,8]$ showed that the tensile residual stresses and the depth of the stressed region tend to increase with feed rate. Schreiber and Schlicht [9] and Brinksmeier [7] found that residual stresses increase with cutting speed. The use of a coolant [10] at low cutting speeds reduces the maximum residual stress and the depth of the stressed region, when compared with the results obtained with dry cutting. Lubrication does not seem to have any significant influence on the residual stress distribution, when the cutting speed increases.

Few studies on turning residual stresses in austenitic stainless steels have been performed. Nagawaka et al. [11], in a study on the influence of surface finishing on residual stresses and stress corrosion cracking susceptibility in Type 18-8 austenitic stainless steel, found longitudinal tensile stresses for rough turning conditions and compressive stresses for fine cutting conditions. Circumferential stresses were tensile and reached high values (close to $700 \mathrm{MPa}$ at the surface). The cutting-affected zone was found to be deeper for a material turned with a high speed steel tool than for the one turned with a cemented carbide tool. Smith and Riley [12], in a study on residual stresses in turned surfaces of $18 \% \mathrm{Cr} 18 \% \mathrm{Mn}$ end ring steel, found a heavily deformed layer with tensile residual stresses extending to a depth of $25 \mu \mathrm{m}$. In the case of AISI 304 steel, Wiesner [13] showed that mechanical and thermal effects were both responsible for the tensile residual stresses in the near-surface region. For the same material, Yang et al. [14] have shown that increasing tool sharpness leads to a diminu- tion in the level of the surface residual stresses for low values of feed rate.

This paper has sought to correlate the above-mentioned recent improvements in material/tool pairing with the residual stress pattern induced by the machining of two types of AISI 316L steel, standard and resulfurized, with coated and uncoated cemented tungsten carbide tools. The results are discussed in terms of the thermal and mechanical loading occuring during machining.

\section{Materials and experimental procedure}

Round bars (150 mm diameter) of two varieties of AISI 316L steel were selected for the study: one standard type (material A); and another with improved machinability, due to the existence of sulfide inclusions (material U). Their chemical composition is presented in the Table 1. The two kinds of steel have an austenitic structure with an approximate grain size of $50 \mu \mathrm{m}$ and a hardness value of close to $170 \mathrm{HV}$.

Orthogonal cutting tests were conducted with uncoated and coated tungsten carbide tools. The uncoated tools, which are referenced as K313 (Kennametal commercial name, ISO K-05/K-15) and H13A (Sandvik commercial name, ISO K10/K-15), are cemented carbide tools. The chemical vapor deposition (CVD) tool coatings employed were triple layer coatings of $\mathrm{TiC}-\mathrm{Al}_{2} \mathrm{O}_{3}-\mathrm{TiN}$ (Kennametal KC850 tool, ISO P-05/P-25), and TiC-TiCN-TiN (Kennametal KC950 tool, ISO P-25/P-45), chosen for their good wear-resistance properties. The orthogonal cutting conditions and the tool geometry are given in Table 2. All of the cutting tests were carried out without cutting fluid.

The orthogonal cutting tests were carried out with a numerically controlled machining center, equipped with analysis set-ups. Cutting force measurements were performed using a Kistler table, delivering the values of the

Table 1

Chemical composition of AISI 316L steels

\begin{tabular}{|c|c|c|c|c|c|c|c|c|c|c|c|c|}
\hline \multirow[t]{2}{*}{ Material } & \multicolumn{12}{|c|}{ Chemical composition (wt\%) } \\
\hline & $\mathrm{C}$ & $\mathrm{Si}$ & $\mathrm{Mn}$ & $\mathrm{Ni}$ & $\mathrm{Cr}$ & Mo & $\mathrm{S}$ & $\mathrm{P}$ & $\mathrm{N}$ & Co & $\mathrm{Cu}$ & $\mathrm{Fe}$ \\
\hline $\mathrm{U}$ & 0.010 & 0.630 & 1.280 & 11.140 & 16.74 & 2.020 & 0.022 & 0.020 & 0.030 & 0.240 & - & balance \\
\hline A & 0.012 & 0.60 & 1.71 & 11.58 & 17.09 & 2.20 & $<0.003$ & 0.025 & - & - & 0.11 & balance \\
\hline
\end{tabular}

Table 2

Cutting conditions and tool geometry

\begin{tabular}{lllll}
\hline Cutting tool reference & $\begin{array}{l}\text { Rake angle } \\
(\gamma)\left({ }^{\circ}\right)\end{array}$ & $\begin{array}{l}\text { Clearance } \\
\text { angle }(\alpha)\left({ }^{\circ}\right)\end{array}$ & $\begin{array}{l}\text { Cutting speed } \\
\left(V_{\mathrm{c}}\right)(\mathrm{m} / \mathrm{min})\end{array}$ & $\begin{array}{l}\text { Feed rate } \\
(f)(\mathrm{mm} / \mathrm{rev})\end{array}$ \\
\hline $\mathrm{K} 313(\mathrm{WC} / \mathrm{Co})$ & 0 and 5 & 5 & $75-200$ & $0.1-0.3$ \\
$\mathrm{KC} 950\left(\mathrm{WC} / \mathrm{Co}+\mathrm{TiC}_{\mathrm{Al}} \mathrm{O}_{3} / \mathrm{TiN}\right)$ & 0 & 5 & $75-200$ & $0.1-0.3$ \\
$\mathrm{KC} 850(\mathrm{WC} / \mathrm{Co}+\mathrm{TiC} / \mathrm{TiCN} / \mathrm{TiN})$ & 0 & 5 & $75-400$ & $0.1-0.3$ \\
$\mathrm{H} 13 \mathrm{~A}(\mathrm{WC} / \mathrm{Co})$ & 0 & 11 & $75-280$ & $0.1-0.3$ \\
\hline
\end{tabular}


Table 3

Parameters used for the X-ray analysis

\begin{tabular}{lllllll}
\hline Test material & Spot area $\left(\mathrm{mm}^{2}\right)$ & $1 / 2 \mathrm{~S}_{2}\left(\mathrm{Mpa}^{-1}\right)$ & $\mathrm{S}_{1}\left(\mathrm{Mpa}^{-1}\right)$ & Wavelength & Radiation & Filter \\
\hline $\mathrm{Fe} \gamma$ & 1 & $6.531 \times 10^{-6}$ & $-1.429 \times 10^{-6}$ & $\mathrm{Mn}$ & $\mathrm{Bragg}$ angle $2 \theta\left(_{\alpha}^{\circ}\right)$ \\
\hline
\end{tabular}

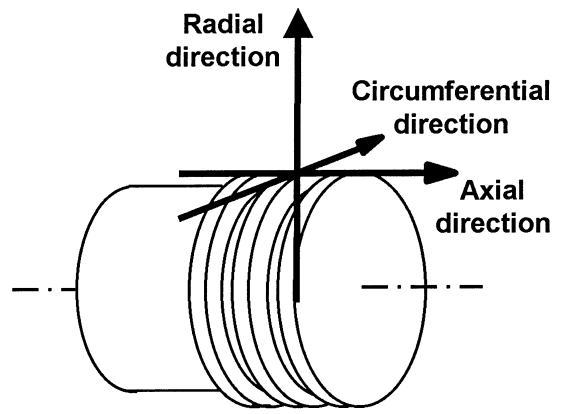

Fig. 1. Analysis directions.

forces the tool sustained in the radial, axial and circumferential directions $^{1}$ (Fig. 1). An original temperature analysis was also performed during cutting, using an infrared CCDcamera $[15,16]$, to reveal the thermal map of the cutting zone for points ranging from $500^{\circ} \mathrm{C}$ to $1000^{\circ} \mathrm{C}$, showing the way heat is evacuated in the tool and the chip, and the interface hot points.

The residual stress state in the workpiece affected by cutting was analyzed by X-ray diffraction using the $\sin ^{2} \psi$ method [17]. Fig. 1 represents the directions of analysis of the residual stresses. Using Eq. (1) and knowledge of the elastic radio-crystallographic constants $S_{1}$ and $S_{2} / 2$, the stresses were calculated from the strain distribution derived from the measured interreticular plane spacing:

$$
\begin{aligned}
\varepsilon_{\phi \psi}= & \frac{1}{2} S_{2}\left[\left(\sigma_{11}^{\phi}-\sigma_{33}^{\phi}\right) \sin ^{2} \psi+\sigma_{13}^{\phi} \sin 2 \psi+\sigma_{33}^{\phi}\right] \\
& +S_{1}\left[\sigma_{11}^{\phi}+\sigma_{22}^{\phi}+\sigma_{33}^{\phi}\right] .
\end{aligned}
$$

The parameters used are given in Table 3. The machined surfaces were electrolytically polished, step-by-step, in order to determine the evolution of the residual stresses with depth. The uncertainty on stress data is less than $50 \mathrm{MPa}$ for depths of less than $200 \mu \mathrm{m}$, but reaches 150$200 \mathrm{MPa}$ for greater depth values, because of existing stress heterogeneity between grains, and a larger grain size in the plastically undeformed core material.

\section{Results}

\subsection{Influence of the tool retraction}

A triaxial stress analysis was first conducted on the surface of the workpiece, the results indicating the radial and

\footnotetext{
${ }^{1}$ In this case the axial forces are negligible when compared with the circumferential and radial forces.
}

shear stress components were negligible, when compared to the high values found in the axial and circumferential directions. For this reason, in the next part of the stress analysis, residual stress determination was done only in these two directions, on the surface as well as in the sublayer.

In order to analyze the residual stress state on the workpiece it was necessary to choose a part of it to be representative of the cutting test. In fact, the part of the surface corresponding to the retraction movement of the tool, at the end of the test, should not be taken into account for the stress analysis. Thus after the cutting tests, circularity profiles were measured on each workpiece, the results showing that it is possible to determine the retraction zone of the tool on the workpiece (Fig. 2). To complete these circularity measurements, surface residual stresses were analyzed all round the workpiece. Measurements were done at different points marked by a specific angular position. The surface residual stresses were plotted in a polar coordinate system as a function of the different angular positions of each measuring point. Fig. 3 shows the circumferential residual stresses (parallel to the cutting direction) determined for material $\mathrm{U}$ machined with the $\mathrm{KC} 850$ tool $\left(V_{\mathrm{c}}=300 \mathrm{~m} / \mathrm{min}\right.$, $f=0.1 \mathrm{~mm} / \mathrm{rev}$.). The results show that the residual stress level is not constant all round the workpiece surface, but varies from 800 to $1000 \mathrm{MPa}$. The evolution of the residual stress profile is found to be strongly correlated to the circularity profile shown in Fig. 2. Consequently, the criter-

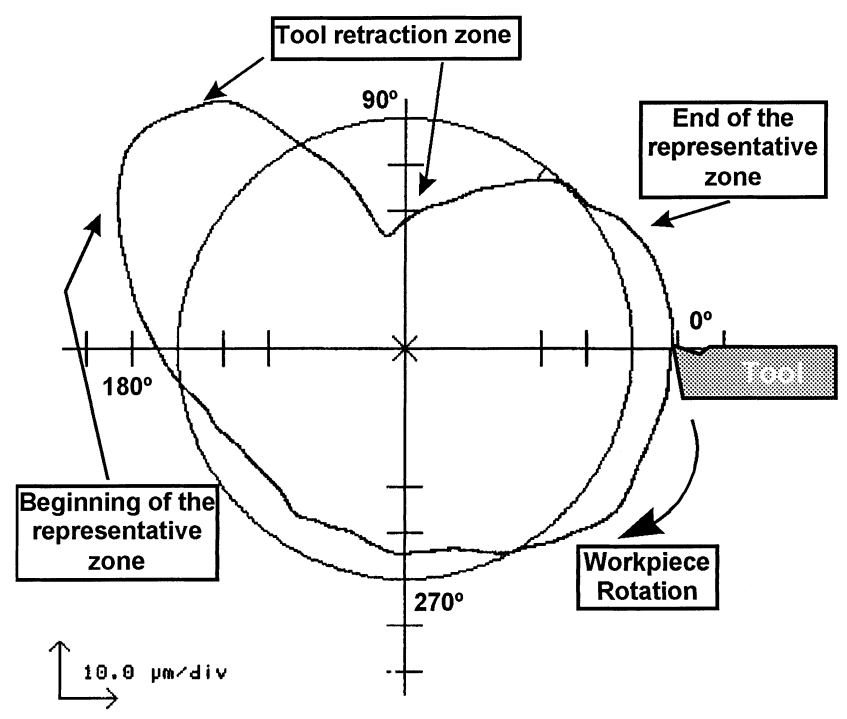

Fig. 2. Example of the circularity profile on the workpiece. 


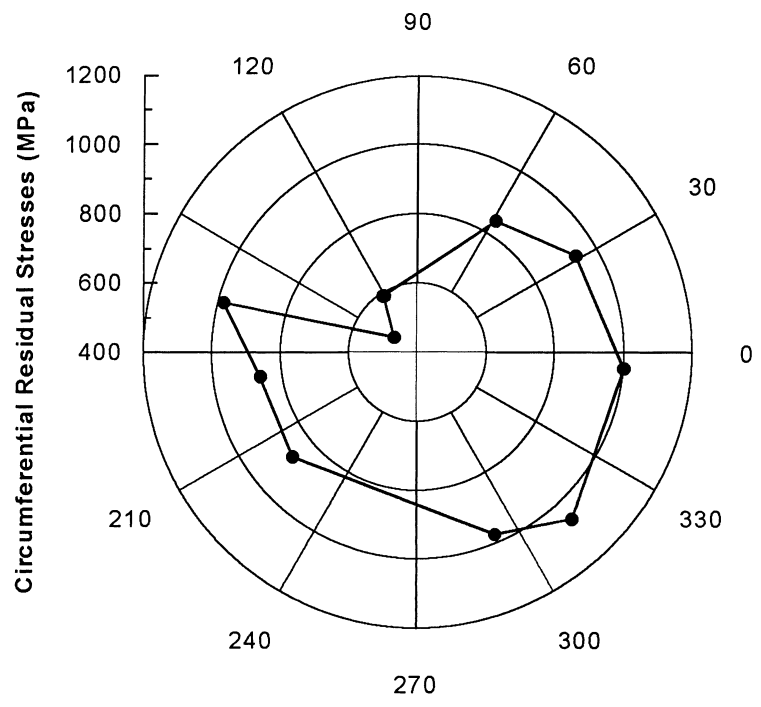

Fig. 3. Surface residual stress evolution around the workpiece surface (Material U; KC850 tool; $V_{\mathrm{c}}=300 \mathrm{~m} / \mathrm{min}, f=0.1 \mathrm{~mm} / \mathrm{rev}$ ).

ion chosen consisted of analyzing the zone of the workpiece located at $180^{\circ}$ angle from the tool retraction zone.

\subsection{Typical residual stress and half-breadth profiles}

A wide range of cutting conditions was investigated. Tensile residual stresses were found on the machined surface in each case. The circumferential stresses were generally greater than axial stresses, with values sometimes reaching around $1000 \mathrm{MPa}$. The level of stresses decreased continuously with depth down to a minimum compressive stress value and then increased and stabilized at a level corresponding to the state of the material before machining, this being true for both the circumferential and the axial residual stresses. In this work it is chosen to present and discuss only circumferential stresses in the following parts of this study. Fig. 4 represents a typical residual stress distribution obtained when machining material $\mathrm{U}$ with a coated tool KC950 with a rake angle of $0^{\circ}$, for a cutting speed of $100 \mathrm{~m} /$ $\mathrm{min}$ and a feed rate of $0.1 \mathrm{~mm} / \mathrm{rev}$. The different parameters are: $\sigma_{\text {circum }} \mathrm{m}$ ax: maximal circumferential stress value; $\sigma_{\text {circum }}$ min: minimal circumferential stress value; and $t_{\mathrm{t}}$ : thickness of the tensile layer on the workpiece.

Fig. 4 also shows the in-depth evolution of the peak halfwidth value for the same cutting conditions. The different characteristic values associated with this profile are $\mathrm{LC}_{\max }$ : the maximal peak half-width value which gives information on the work-hardening state of the surface, the peak halfwidth value determined on the workpiece surface showing a significant surface work-hardening, when compared to the undeformed core material value; and $t_{\mathrm{LC}}$ : the cuttingaffected depth, which was taken as the value for which LC reached 1.2 times the nominal value of the undeformed material, ${ }^{2}$ this cutting-affected depth varying from 70 to 350 $\mu \mathrm{m}$.

\subsection{Typical temperature distribution around the tool tip}

Fig. 5 shows the thermal maps obtained with the CCD infrared camera, for machining tests performed with uncoated and coated cemented carbide tools. [18]. In these examples, the hottest points are on the flank face (the tool/ workpiece interface), at $900^{\circ} \mathrm{C}$ and $780^{\circ} \mathrm{C}$. This kind of analysis was done throughout the investigation for all cutting parameters, and has allowed discussion about the thermomechanical loading effects on the near surface residual stress level.

\subsection{Influence of machining parameters on residual stresses}

\subsubsection{Influence of cutting speed}

The influence of cutting speed variation was investigated for a given feed rate of $0.1 \mathrm{~mm} / \mathrm{rev}$ and for the material/tool
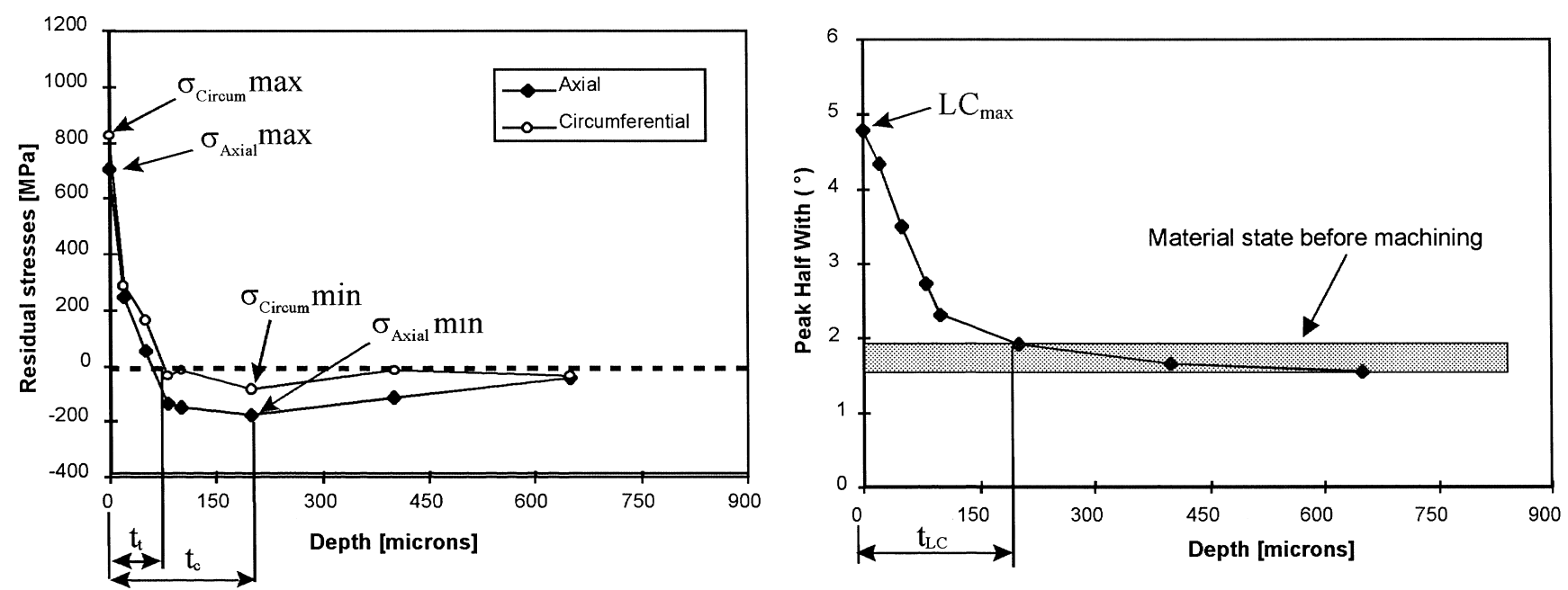

Fig. 4. Typical shape of residual stress and peak breadth profile (Material $\mathrm{U} ; \mathrm{KC} 950\left(0^{\circ}\right)$ tool; $\left.V_{\mathrm{c}}=100 \mathrm{~m} / \mathrm{min}, f=0.1 \mathrm{~mm} / \mathrm{rev}\right)$. 


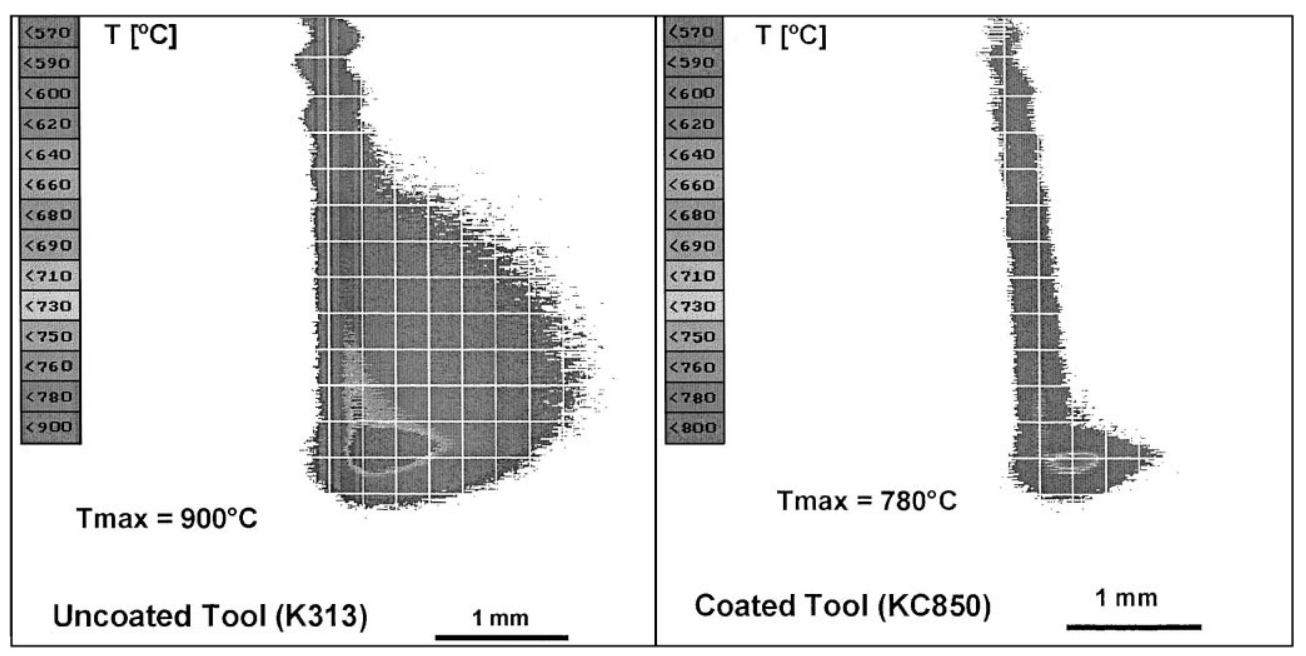

Fig. 5. Temperature distribution in the cutting zone for an uncoated and coated tool (Material A; $V_{\mathrm{c}}=150 \mathrm{~m} / \mathrm{min} ; f=0.1 \mathrm{~mm} / \mathrm{rev}$ ).
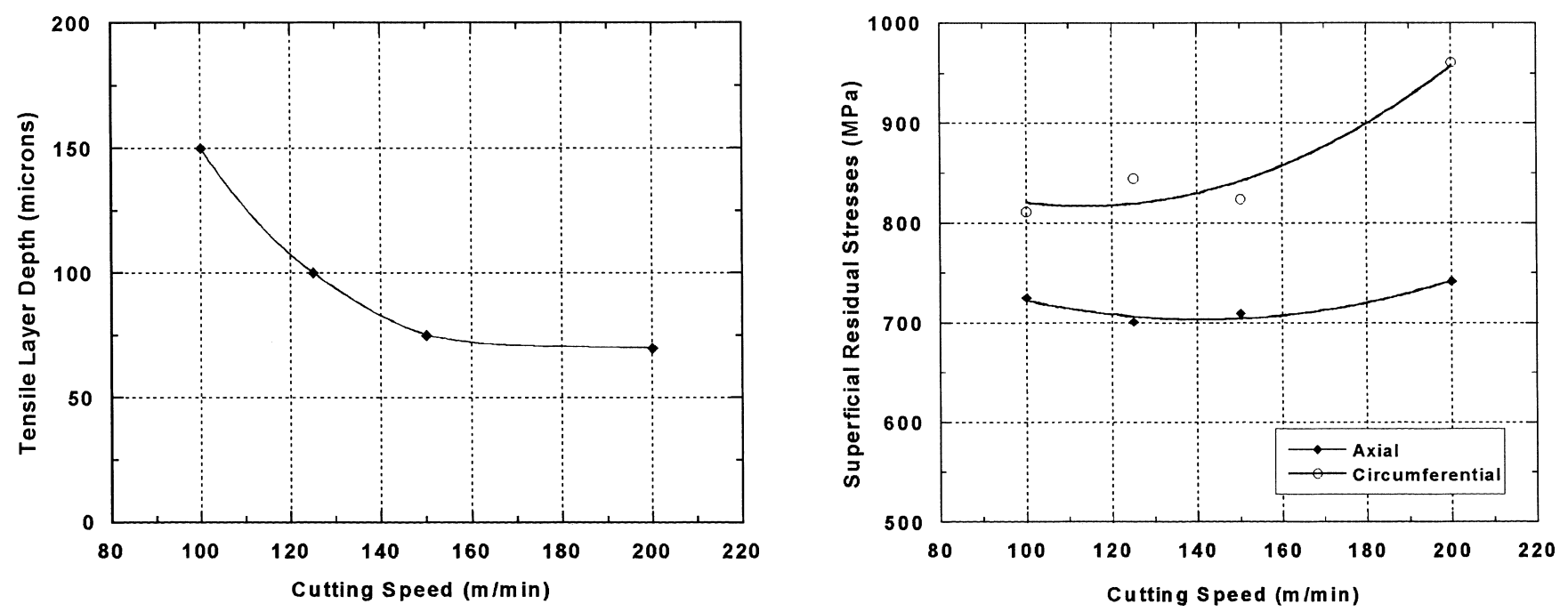

Fig. 6. Surface residual stresses and tensile layer depth as functions of cutting speed (Material U; KC950 $\left(0^{\circ}\right)$ tool).

couple $\mathrm{KC} 950\left(0^{\circ}\right) / \mathrm{U}$. Results show an increase of $140 \mathrm{MPa}$ in the surface residual stress when the cutting speed increased from 100 to $200 \mathrm{~m} / \mathrm{min}$ (Table 4 and Fig. 6).

However, the thickness of the tensile layer decreased with the cutting speed. If these results are linked to cutting forces, analysis shows that both the cutting force and feed force tend to diminish as the cutting speed increases (Fig. 7). The subsurface stress values also tended to be less compressive with increase in the cutting speed and their minimal values were reached deeper into the workpiece surface. As for the peak half-width values, it can be seen from Table 4 that LC increases with increase in the cutting speed.

Table 4

Influence of the cutting speed on the characteristic parameters of the stress analysis for material $\mathrm{U}$ KC950 $\left(0^{\circ}\right)$ tool and $f=0.1 \mathrm{~mm} / \mathrm{rev}$

\begin{tabular}{|c|c|c|c|c|c|c|c|c|}
\hline \multirow[t]{2}{*}{$V_{\mathrm{c}}(\mathrm{m} / \mathrm{min})$} & \multicolumn{4}{|c|}{ Residual stresses } & \multirow[t]{2}{*}{ Peak breadth LC $\left({ }^{\circ}\right)$} & \multicolumn{3}{|c|}{ Cutting-affected depth } \\
\hline & $\begin{array}{l}\sigma_{\text {circum, max }} \\
(\mathrm{MPa})\end{array}$ & $\begin{array}{l}\sigma_{\text {axial, max }} \\
(\mathrm{MPa})\end{array}$ & $\begin{array}{l}\sigma_{\text {circum, min }} \\
(\mathrm{MPa})\end{array}$ & $\begin{array}{l}\sigma_{\text {axial, }} \text { min } \\
(\mathrm{MPa})\end{array}$ & & $t_{\mathrm{t}}(\mu \mathrm{m})$ & $t_{\mathrm{c}}(\mu \mathrm{m})$ & $t_{\mathrm{LC}}(\mu \mathrm{m})$ \\
\hline 100 & 820 & 800 & -90 & -140 & 4.53 & 150 & 400 & 100 \\
\hline 125 & 850 & 700 & -70 & -120 & 4.70 & 100 & 200 & 150 \\
\hline 150 & 830 & 710 & -80 & -180 & 4.80 & 75 & 200 & 180 \\
\hline 200 & 960 & 820 & -40 & -180 & 4.80 & 70 & 100 & 90 \\
\hline
\end{tabular}




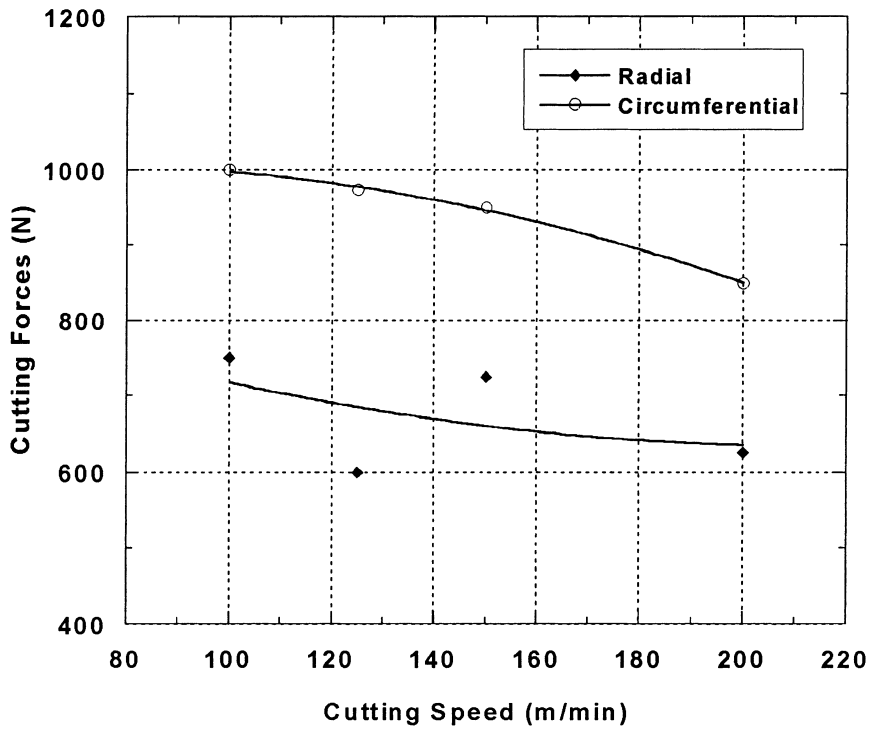

Fig. 7. Cutting forces as functions of cutting speed (Material U; KC950 $\left(0^{\circ}\right)$ tool; $\left.f=0.1 \mathrm{~mm} / \mathrm{rev}\right)$.

\subsubsection{Influence of feed rate}

Depth profiles of residual stresses were obtained for different values of feed rate. As an example, Fig. 8 represents the stress gradient for a feed rate variation of $0.1-$ $0.25 \mathrm{~mm} / \mathrm{rev}$. The cutting speed was fixed at $125 \mathrm{~m} / \mathrm{min}$, and the material/tool pairing was $\mathrm{KC} 950\left(0^{\circ}\right) / \mathrm{U}$. The minimal stress values were more compressive and were located deeper in the workpiece as the feed rate increased, although the surface residual stresses barely varied with feed rate. An obvious increase in the thickness of the tensile layer can be observed (Fig. 9). These results can be explained considering that an increasing value of feed rate leads to an augmentation of the cutting and feed forces (Fig. 9). Thus, the tool compressive effect on the workpiece gains importance, and this results in a thicker and more severely work-hardened layer.

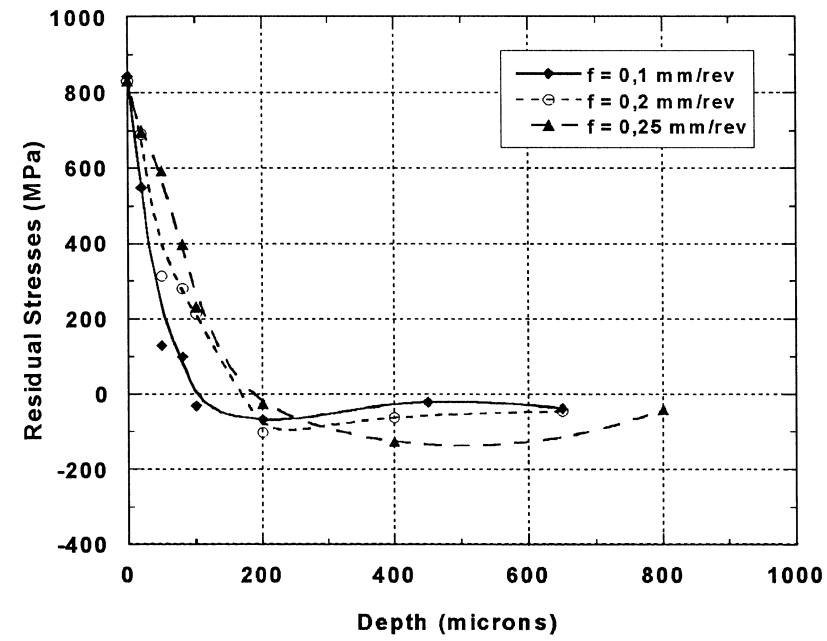

\subsubsection{Influence of tool nature and geometry}

The influence of tool geometry (rake angle variation) has been also investigated for both of the machined materials (A and $\mathrm{U}$ ) in the case of the uncoated cemented carbide tool (K313) in order to avoid problems encountered with coated tools (the roundness of the tool nose region, which could affect the results). The depth-stress profiles obtained for material $\mathrm{A}$, show that an increase in the rake angle from $0^{\circ}$ to $5^{\circ}$ led to a slight decrease in the surface residual stress values (40 MPa). The thickness of the tensile layer (Table 5) was slightly increased and the minimum compressive stress values were smaller, but were reached deeper in the workpiece. No clear variation of the depth of the cutting-affected layer with rake angle variation was noted.

As for the case of material $\mathrm{U}$, a more important decrease of the surface stresses was observed as rake angle increased. However, the thickness of the tensile layer decreased perceptibly.

As a conclusion, no obvious connection could be found between the rake angle and the thickness of the tensile layer, whereas the rake angle value seemed to play an important role in the surface residual stresses and the sub-surface minimum compressive stresses: this decreases with the rake angle. This result could be related to the evolution of cutting and feed forces, which diminished as the rake angle passed from $0^{\circ}$ to $5^{\circ}$ (Fig. 10).

The influence of the tool coating on the residual stresses was studied for the three cutting tools (K313, KC850 and KC950). The main comparison was done between K313 and KC950, for which the "stable" cutting conditions corresponding to low cutting forces and good chip formation were close $\left(V_{\mathrm{c}}=150 \mathrm{~m} / \mathrm{min}\right.$ and $\left.f=0.1 \mathrm{~mm} / \mathrm{rev}\right)$. For the KC850 tool the stable cutting condition was located around $300 \mathrm{~m} /$ $\mathrm{min}$ and $0.1 \mathrm{~mm} / \mathrm{rev}$., which made direct comparison difficult. The results are summed up in Table 6, and show that the surface residual stresses were a little smaller for the KC950 tool, but the cutting-affected depth appeared to increase. For

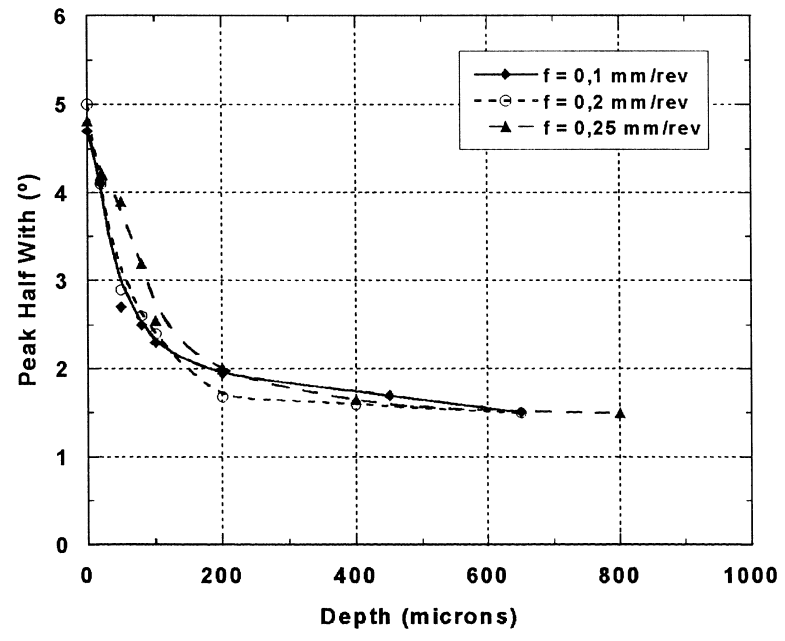

Fig. 8. Residual tangential stress and peak breadth profiles as functions of feed rate (Material $\mathrm{U} ; \mathrm{KC} 950\left(0^{\circ}\right)$ tool; $\left.V_{\mathrm{c}}=125 \mathrm{~m} / \mathrm{min}\right)$. 

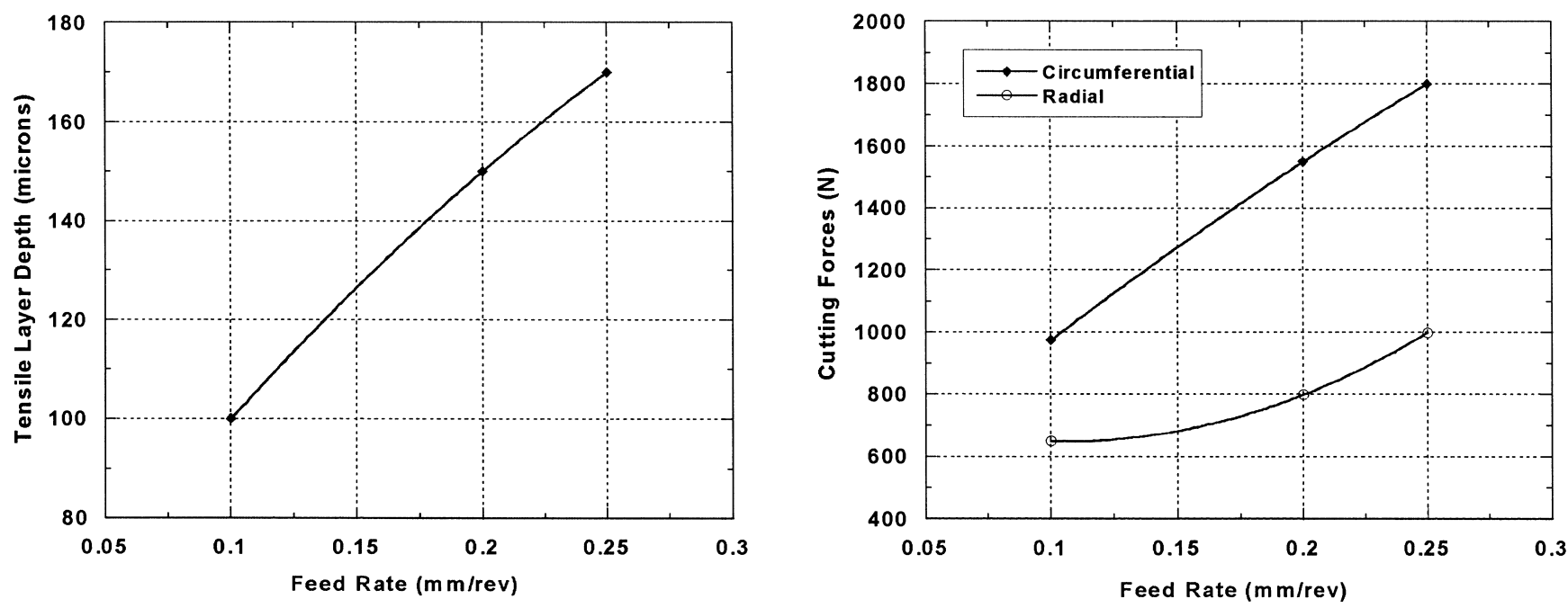

Fig. 9. Tensile layer depth and cutting forces as functions of feed rate (Material U; KC950 $\left(0^{\circ}\right)$ tool; $V_{\mathrm{c}}=125 \mathrm{~m} / \mathrm{min}$ ).
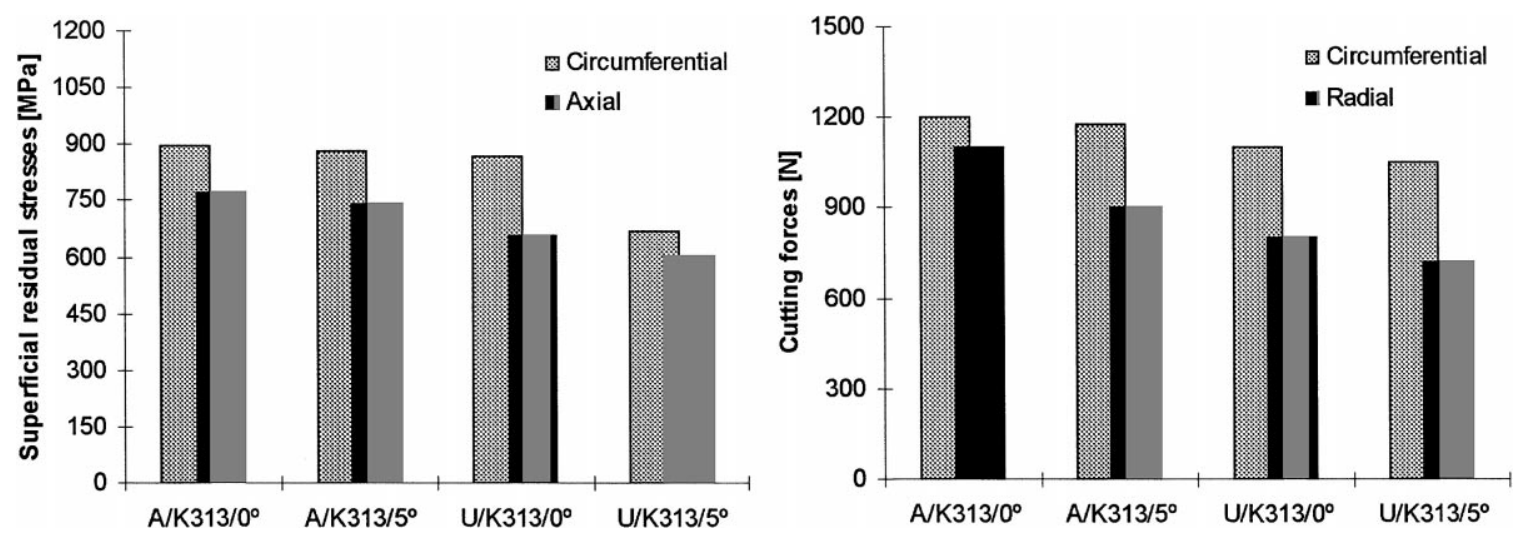

Fig. 10. Surface residual stresses and cutting forces as functions of the rake angle $\left(V_{\mathrm{c}}=150 \mathrm{~m} / \mathrm{min} ; f=0.1 \mathrm{~m} / \mathrm{rev}\right)$.

Table 5

Influence of the rake angle on the characteristic parameters of the stress analysis for $V_{\mathrm{c}}=150 \mathrm{~m} / \mathrm{min}$ and $f=0.1 \mathrm{~mm} / \mathrm{rev}$

\begin{tabular}{|c|c|c|c|c|c|c|c|c|}
\hline \multirow[t]{2}{*}{ Rake angle $\left({ }^{\circ}\right)$} & \multicolumn{4}{|c|}{ Residual stresses } & \multirow[t]{2}{*}{ Peak breadth LC $\left(^{\circ}\right)$} & \multicolumn{3}{|c|}{ Cutting-affected depth } \\
\hline & $\begin{array}{l}\sigma_{\text {circum. max }} \\
(\mathrm{MPa})\end{array}$ & $\begin{array}{l}\sigma_{\text {axial, } \max } \\
\text { (MPa) }\end{array}$ & $\begin{array}{l}\sigma_{\text {circum,. } \min } \\
(\mathrm{MPa})\end{array}$ & $\begin{array}{l}\sigma_{\text {axial, min }} \\
(\mathrm{MPa})\end{array}$ & & $t_{\mathrm{t}}(\mathrm{mm})$ & $t_{\mathrm{c}}(\mathrm{mm})$ & $t_{\mathrm{LC}}(\mathrm{mm})$ \\
\hline $\mathrm{A} / \mathrm{K} 3130^{\circ}$ & 920 & 780 & -190 & -170 & 4.62 & 100 & 160 & 230 \\
\hline $\mathrm{A} / \mathrm{K} 3135^{\circ}$ & 880 & 740 & -120 & -200 & 4.66 & 115 & 260 & 230 \\
\hline $\mathrm{U} / \mathrm{K} 3130^{\circ}$ & 870 & 660 & -160 & -275 & 4.50 & 110 & 300 & 120 \\
\hline $\mathrm{U} / \mathrm{K} 3135^{\circ}$ & 670 & 600 & -80 & -160 & 4.61 & 60 & 200 & 150 \\
\hline
\end{tabular}

Table 6

Influence of tool nature on the characteristic parameters of the stress for material $\mathrm{U}$ and $f=0.1 \mathrm{~mm} / \mathrm{rev}$

\begin{tabular}{|c|c|c|c|c|c|c|}
\hline \multirow[t]{2}{*}{ Tool (cutting speed) } & \multicolumn{2}{|c|}{ Residual stresses } & \multirow[t]{2}{*}{ Peak breadth LC $\left(^{\circ}\right)$} & \multicolumn{3}{|c|}{ Cutting affected depth } \\
\hline & $\begin{array}{l}\sigma_{\text {circum., }} \max \\
(\mathrm{MPa})\end{array}$ & $\begin{array}{l}\sigma_{\text {circum., }} \text { min } \\
(\mathrm{MPa})\end{array}$ & & $t_{\mathrm{t}}(\mu \mathrm{m})$ & $t_{\mathrm{c}}(\mu \mathrm{m})$ & $t_{\mathrm{LC}}(\mu \mathrm{m})$ \\
\hline $\mathrm{K} 313\left(0^{\circ}\right)\left(V_{\mathrm{c}}=150 \mathrm{~m} / \mathrm{min}\right)$ & 870 & -160 & 4.50 & 100 & 300 & 150 \\
\hline $\operatorname{KC950}\left(0^{\circ}\right)\left(V_{\mathrm{c}}=150 \mathrm{~m} / \mathrm{min}\right)$ & 830 & -80 & 4.80 & 80 & 200 & 180 \\
\hline $\operatorname{KC} 850\left(0^{\circ}\right)\left(V_{\mathrm{c}}=300 \mathrm{~m} / \mathrm{min}\right)$ & 1100 & -50 & 4.78 & 150 & 200 & 200 \\
\hline
\end{tabular}


the KC850 tool, the surface stresses and cutting-affected depth were perceptibly greater than for the $\mathrm{K} 313$ and $\mathrm{KC}$ 950 tools. This is explained mainly by the significant increase in the cutting speed [7,9].

A thermal analysis was also done during the cutting experiments, the results showing that the level of temperature reached at the tool/chip and tool/workpiece interface was greater for the uncoated tool, being close to $900^{\circ} \mathrm{C}$. Regarding the coated tool, the maximum temperature reached in the same zone was less than $780^{\circ} \mathrm{C}$ (Fig. 5).

It can be said from this analysis of the tool coating influence that, for comparable stable cutting conditions, the use of a coating leads to a reduction in the surface stresses, but tends to increase the thickness of the workhardened zone.

\subsubsection{Influence of chemical treatment on the workpiece (materials $A$ and $U$ )}

In agreement with the above, the resulfurized treatment had an influence on workpiece integrity as far as surface residual stresses are concerned. As can be seen in Table 5, in the case of material $U$, the residual stresses were slightly lower than for the material A. Other tests show that this difference was more significant when using the H13A tool [19].

\section{Discussion}

It was difficult for this work to propose a quantitative interpretation of the thermal and mechanical effects on the generation of residual stresses on the workpiece surface because these effects are interdependent. Nevertheless, it is possible to point out the qualitative evolution of the residual stresses with tool nature and cutting parameters.

\subsection{Influence of tool nature}

For both uncoated and coated tools, high temperature levels are reached in the cutting zone. This is responsible for a much of the high level of tensile residual stresses found in the machined parts. The low friction coefficient of the coated tool $[20,21]$ limits temperature elevation and could explain the slight decrease in surface stresses, and the decrease in the thickness of the tensile layer.

However, this did not explain the effect of increased workhardening observed on the workpiece. In fact, the coating operation tends to round the tool nose region and increases the tool radius [22]. This could result in more interaction between the tool nose region and the workpiece, which may induce a deeper shearing effect below the cutting edge and affect the peak half-width values and the cutting-affected depth.

From these observations, it can be concluded that thermal effects due to friction make a major contribution on the surface region of the workpiece, whereas the mechanical effect is enhanced because of the increased tool roundness, due to the coating. This is responsible for the work-hardening below the sub-surface.

\subsection{Influence of rake angle}

No clear connection between this parameter and the thickness of the tensile layer and the cutting-affected depth was observed. However, the cutting forces decrease when the cutting angles increase and this leads to fewer compressive stresses. This means that the compressive mechanical effects are less important when a cutting tool with a positive rake angle is employed.

\subsection{Influence of the cutting speed}

Increasing the cutting speed leads to an augmentation of the surface residual stresses and a diminution of the thickness of the tensile layer. These results are in agreement with those obtained by Wiesner [13] in the orthogonal machining of AISI 304 steels. The influence of cutting speed is explained by the chip speed flow in the cutting zone tending to increase with cutting speed, leading to a greater heat evacuation. Moreover, the low thermal diffusivity of austenitic steel implies that only a small amount of heat passes in to the workpiece and the tool, as can be seen on thermal maps of such conditions, the major part being carried away with the chip. This causes a small increase in the cutting energy in this zone, which is only sufficient to affect the workpiece surface region, by increasing the surface stresses. Therefore, it leads to a decrease in the thickness of the tensile layer. This is in agreement with experimental thermal analysis observations which, in the case of the KC850 tool for example, were a large increase in chip temperature but a small increase in the tool/workpiece interface [22]. This highlighted the greater heat evacuation in the chip, leading to a decrease in the heat-affected zone of the workpiece.

\subsection{Influence of feed rate}

The influence of feed rate on the generated surface residual stresses is relatively small. It is seen however, that increasing values of feed rate tend to increase the compressive stress values in the sub-surface, and the thickness of the tensile layer. This can be explained largely by a mechanical effect causing the augmentation of the compressive zone in the region of the workpiece situated below the cutting edge, leading to greater elastic relaxation after machining [13]. The augmentation of the compressive stress value may be related to stress redistribution in this zone, balancing the increasing tensile layer.

It can be a state from this analysis that mechanical effects seem to play a role not only in the surface tensile stresses but also in the sub-surface, within $800 \mu \mathrm{m}$. The thermal effects are more localized in the surface region of the workpiece. 


\section{Conclusions}

Residual stresses induced by orthogonal cutting of standard and resulfurized AISI 316L steels were investigated by $\mathrm{X}$-ray diffraction for a wide range of cutting conditions, different tool geometries and tool coatings. Moreover, during the tests, an experimental analysis of the temperature field in the cutting zone in association with cutting force measurement enabled discussion of the physical mechanisms involved in residual stress generation.

For all material/tool pairing, high tensile residual stress values of around $800 \mathrm{MPa}$, associated with strong workhardening, are found in the workpiece surface. These tensile stresses are attributed to local thermal effects arising from heat generation during cutting, leading to high temperatures in the tool/workpiece contact zone (close to $900^{\circ} \mathrm{C}$ ) in the tool nose region, in particular at greater cutting speeds. The thickness of the tensile layer was found to decrease with cutting speed, but increase for high feed rate values. When the material was treated for machinability enhancement, the temperatures were lower (about $700^{\circ} \mathrm{C}$ ), and the residual stress level consequently decreased.

In addition, mechanical effects appeared to play a significant role as far as the tool coating was concerned: even if a TiN coated tool seemed to reduce friction and thus the temperature level (lower than $800^{\circ} \mathrm{C}$ ) of the workpiece, it still affected the residual stress distribution by increasing the depth of the severely strained region (20\% increase). This was associated with the chip formation mechanism and modification of the tool nose region.

Feed rate had a strong influence on the shape of the residual stress profile (the depth of the compressive point; the cutting affected zone). As it increased, this parameter increased the temperature levels and also positively controlled the chip formation. Mechanical and thermal effects were fully interdependent in this case.

In addition to thermo-mechanical interdependent explanations (through cutting zone temperature and cutting force analyses), structural elements can be used: the chip shape and strain localization must not be forgotten [23]. Since the chip flow mode was homogeneous (serrated chips), these parameters were not significant in this present study.

\section{Acknowledgements}

J.C. Outeiro is grateful to the PRAXIS XXI Programe (Portugal) for financial support for this work.

\section{References}

[1] E.M. Trent, Metal Cutting, Butterworth/Heinemann, London, 1991.

[2] E.K. Henriksen, Residual stresses in machined surfaces, Trans. ASME 73 (January 1951), 265-278.
[3] K. Okushima, Y. Kakino, A study on the residual stress produced by metal cutting, Memoirs of the Faculty of Engineering, Kuyoto 34 (1972) 234-248.

[4] C.R. Liu, M.M. Barash, The mechanical state of the sub-layer of a surface generated by chip removal process, Part I: Cutting with a sharp tool, Trans. ASME 98(4) (1976) 257-264.

[5] Y. Matsumoto, M.M. Barash, C.R. Liu, Effect of hardness on surface integrity of AISI 4340 steel, ASME J. Eng. Indust. 108 (1986) 169175.

[6] D.W. Wu, Y. Matsumoto, The effect of hardness on residual stresses in orthogonal machining of AISI 4340 Steel, ASME J. Eng. Indust. 112 (1990) 245-252.

[7] E. Brinksmeier, Residual stresses in hard metal cutting, Residual Stresses Sci. Technol. 2 (1987) 839-847.

[8] B. Scholtes, Residual stresses introduced by machining, in: Advance in Surface Treatments, Technology-Applications-Effects, International Guidebook on Residual Stresses, vol. 4, Pergamon Press, Oxford, 1987, pp. 59-71.

[9] E. Schreiber, H. Schlicht, Residual stresses after turning of hardened components, Residual Stresses Sci. Technol. 2 (1987) 853-860.

[10] S. Jeelani, J.A. Bailey, Residual stress distribution in machining annealed 18\% nickel maraging steel, ASME J. Eng. Mater. Technol. 108 (1986) 93-98.

[11] Y. Nagawaka, K. Usami, A. Minato, T. Tamamura, R. Sasaki, A. Naruse, Effects of surface finish on residual stress distribution and stress corrosion cracking susceptibility of type 304 austenitic stainless steel in a boiling $42 \% \mathrm{MgCl}_{2}$ solution, ICM3, vol. 2, Cambridge, 1979, pp. 603-610.

[12] G.M. Smith, J.F. Riley, Residual Stresses in Austenitic Generator End-Rings, ICRS2, Elsevier Applied Science, Amsterdam, 1989, pp. 728-733.

[13] C. Wiesner, Residual stresses after orthogonal machining of AISI 304: numerical calculation of the thermal component and comparison with experimental results, Metall. Trans. A 23 (1989) 989-996.

[14] D.Y. Yang, T.R. Watkins, K.J. Kozaczek, C.R. Hubbard, O.B. Cavin, Surface residual stresses in machined austenitic stainless steels, Wear 194 (1996) 168-173.

[15] C. Le Calvez, Etude des aspects thermiques et métallurgiques de la coupe orthogonale d'un acier au carbone, Thesis, Ecole Nationale Supérieure Des Arts Et Métiers, Paris, 1995.

[16] R. M'Saoubi, C. Le Calvez, J.-L. Lebrun, Influence of tool nature and coating on the temperature distribution during chip formation in orthogonal cutting of steels, Matériaux et Techniques 9/10 (1997) 37-42.

[17] G. Maeder, J.L. Lebrun, J.M. Sprauel, Détermination par diffraction des rayons $\mathrm{X}$ des contraintes internes. Aspects macro et microscopiques, Ecole d'Eté d'Oléron: Physique et Mécanique de la Mise en Forme des Matériaux, Presses du CNRS-IRSID, 1990.

[18] J.-L. Lebrun, R. M'Saoubi, B. Changeux, A new method for cutting tool temperature measurement using CCD infrared technique: The influence of tool nature and coating, CIRP International Workshop on Modeling of Machining Operations, Atlanta, Georgia, USA, 19 May 1998.

[19] J. Outeiro, Comportamento do aço AISI 316L em Torneamento Ortogonal, Thesis, Department of Mechanics Engineering of University of Coimbra, Coimbra, 1998.

[20] O. Bletton, R. Duet, R. Heritier, Usinabilité des aciers inoxydables, in: P. Lacombe, B. Baroux, G. Beranger (Eds.), Les aciers inoxydables, Les Editions de Physique, 1990, pp. 776-779.

[21] D.A. Stephenson, J.S. Agapiou, Metal Cutting - Theory and Practice, Marcel Dekker, New York, 1997.

[22] R. M'Saoubi, Aspects thermiques et microstructuraux de la coupe, Thesis, Ecole Nationale Supérieure des Arts et Métiers, Paris, 1998.

[23] L. Jiang, A. Roos, P. Liu, The influence of austenite grain size and its distribution on chip deformation and tool life during machining of AISI 304L, Metall. Mater. Trans. A 28A, 1997 2415-2422. 